Cochrane Database of Systematic Reviews

\title{
Single crowns versus conventional fillings for the restoration of root-filled teeth (Review)
}

Sequeira-Byron P, Fedorowicz Z, Carter B, Nasser M, Alrowaili EF

Sequeira-Byron P, Fedorowicz Z, Carter B, Nasser M, Alrowaili EF.

Single crowns versus conventional fillings for the restoration of root-filled teeth.

Cochrane Database of Systematic Reviews 2015, Issue 9. Art. No.: CD009109.

DOI: 10.1002/14651858.CD009109.pub3.

www.cochranelibrary.com 
TABLE OF CONTENTS

ABSTRACT 1

PLAIN LANGUAGE SUMMARY

SUMMARY OF FINDINGS

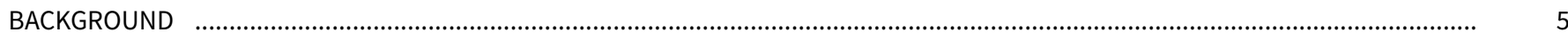

OBJECTIVES

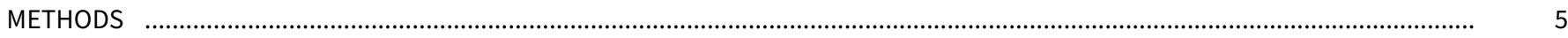

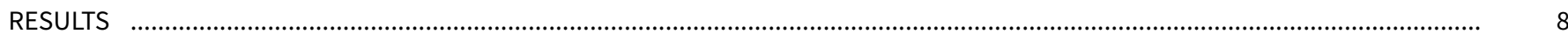

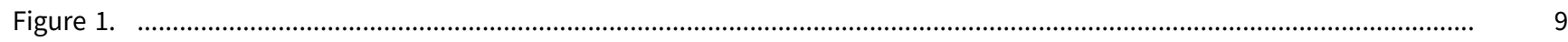

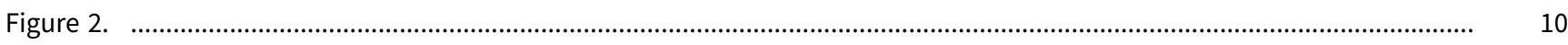

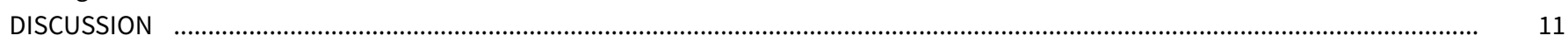

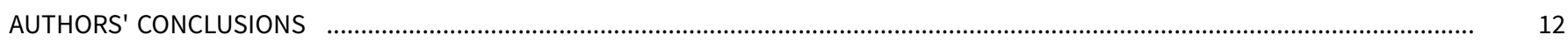

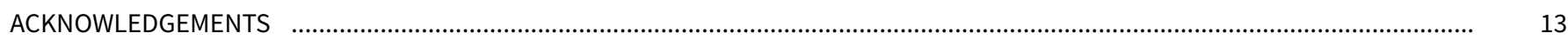

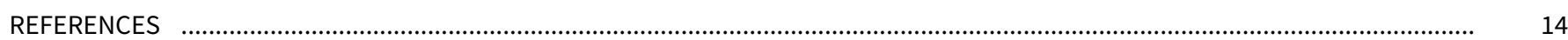

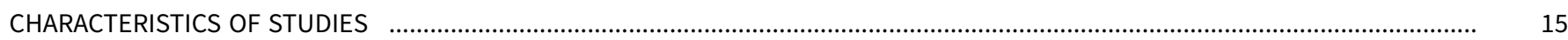

DATA AND ANALYSES

Analysis 1.1. Comparison 1 Composite + crown versus composite only, Outcome 1 All years, failure of the restoration (non- 18 catastrophic).

Analysis 1.2. Comparison 1 Composite + crown versus composite only, Outcome 2 All years, failure of post (non-catastrophic). . 18

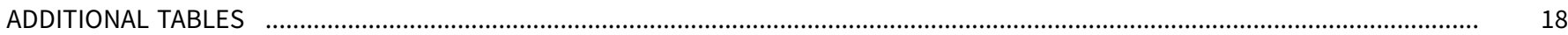

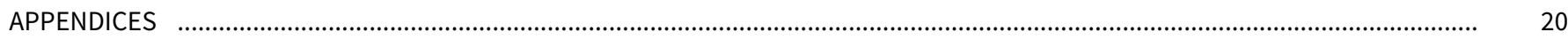

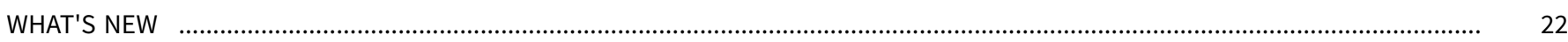

CONTRIBUTIONS OF AUTHORS

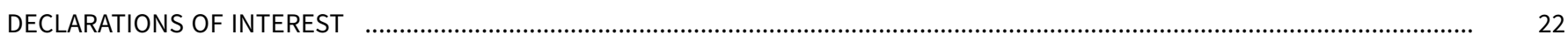

SOURCES OF SUPPORT

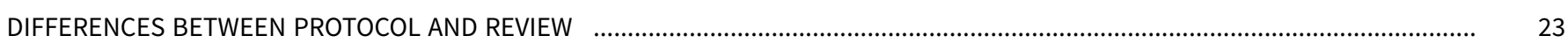

INDEX TERMS 
[Intervention Review]

\title{
Single crowns versus conventional fillings for the restoration of root- filled teeth
}

Patrick Sequeira-Byron¹, Zbys Fedorowicz², Ben Carter ${ }^{3}$, Mona Nasser ${ }^{4}$, Eman F Alrowaili 5

1Department of Preventive, Restorative and Pediatric Dentistry, University of Bern, Bern, Switzerland. 2Bahrain Branch, Cochrane, Awali, Bahrain. ${ }^{3}$ Institute of Primary Care \& Public Health, Cardiff University School of Medicine, Cardiff, UK. ${ }^{4}$ Peninsula Dental School, Plymouth University Peninsula Schools of Medicine and Dentistry, Plymouth, UK. ${ }^{5}$ Oral and Dental Health Services, Ministry of Health, Manama, Bahrain

Contact: Patrick Sequeira-Byron, Department of Preventive, Restorative and Pediatric Dentistry, University of Bern, Freiburgstrasse 7 , Bern, Bern, CH-3010, Switzerland. patrick.sequeira@zmk.unibe.ch.

Editorial group: Cochrane Oral Health Group.

Publication status and date: New search for studies and content updated (no change to conclusions), published in Issue 9, 2015.

Citation: Sequeira-Byron P, Fedorowicz Z, Carter B, Nasser M, Alrowaili EF. Single crowns versus conventional fillings for the restoration of root-filled teeth. Cochrane Database of Systematic Reviews 2015, Issue 9. Art. No.: CD009109. DOI: 10.1002/14651858.CD009109.pub3.

Copyright $\odot 2015$ The Cochrane Collaboration. Published by John Wiley \& Sons, Ltd.

\begin{abstract}
A B S T R A C T

\section{Background}

Endodontic treatment involves removal of the dental pulp and its replacement by a root canal filling. Restoration of root filled teeth can be challenging due to structural differences between vital and non-vital root-filled teeth. Direct restoration involves placement of a restorative material e.g. amalgam or composite, directly into the tooth. Indirect restorations consist of cast metal or ceramic (porcelain) crowns. The choice of restoration depends on the amount of remaining tooth, and may influence durability and cost. The decision to use a post and core in addition to the crown is clinician driven. The comparative clinical performance of crowns or conventional fillings used to restore root-filled teeth is unknown. This review updates the original, which was published in 2012.
\end{abstract}

\section{Objectives}

To assess the effects of restoration of endodontically treated teeth (with or without post and core) by crowns versus conventional filling materials.

\section{Search methods}

We searched the following databases: the Cochrane Oral Health Group's Trials Register, CENTRAL, MEDLINE via OVID, EMBASE via OVID, CINAHL via EBSCO, LILACS via BIREME. We also searched the reference lists of articles and ongoing trials registries.There were no restrictions regarding language or date of publication. The search is up-to-date as of 26 March 2015.

\section{Selection criteria}

Randomised controlled trials (RCTs) or quasi-randomised controlled trials in participants with permanent teeth that have undergone endodontic treatment. Single full coverage crowns compared with any type of filling materials for direct restoration or indirect partial restorations (e.g. inlays and onlays). Comparisons considered the type of post and core used (cast or prefabricated post), if any.

\section{Data collection and analysis}

Two review authors independently extracted data from the included trial and assessed its risk of bias. We carried out data analysis using the 'treatment as allocated' patient population, expressing estimates of intervention effect for dichotomous data as risk ratios, with $95 \%$ confidence intervals $(\mathrm{Cl})$. 


\section{Main results}

We included one trial, which was judged to be at high risk of performance, detection and attrition bias. The 117 participants with a rootfilled, premolar tooth restored with a carbon fibre post, were randomised to either a full coverage metal-ceramic crown or direct adhesive composite restoration. None experienced a catastrophic failure (i.e. when the restoration cannot be repaired), although only 104 teeth were included in the final, three-year assessment. There was no clear difference between the crown and composite group and the composite only group for non-catastrophic failures of the restoration ( $1 / 54$ versus $3 / 53$; RR $0.33 ; 95 \% \mathrm{Cl} 0.04$ to 3.05 ) or failures of the post ( $2 / 54$ versus 1/53; RR 1.96; $95 \% \mathrm{Cl} 0.18$ to 21.01 ) at three years. The quality of the evidence for these outcomes is very low. There was no evidence available for any of our secondary outcomes: patient satisfaction and quality of life, incidence or recurrence of caries, periodontal health status, and costs.

\section{Authors' conclusions}

There is insufficient evidence to assess the effects of crowns compared to conventional fillings for the restoration of root-filled teeth. Until more evidence becomes available, clinicians should continue to base decisions about how to restore root-filled teeth on their own clinical experience, whilst taking into consideration the individual circumstances and preferences of their patients.

\section{PLAIN LANGUAGE SUMMARY}

\section{Single crowns or routine fillings for the restoration of root-filled teeth}

\section{Review question}

This review (an update of the original published in 2012) has been conducted to assess whether there is a difference in the effects of restoration of root-filled teeth (with or without post and core) by indirect restorations (commonly crowns, inlays, or onlays) compared to conventional filling materials placed directly into the tooth.

\section{Background}

Root filling is a fairly routine dental procedure in which the injured or dead nerve of a tooth is removed and replaced by a root canal filling. However, the restoration of root-filled teeth can be quite challenging as these teeth tend to be weaker than healthy ones. A dentist may use crowns (restorations made outside of the mouth and then cemented into place) or conventional fillings (direct filling with materials such as amalgam or composite/plastic resin). Although crowns may help to protect root-filled teeth by covering them, conventional fillings demand less in terms of time, costs and removal of tooth structure.

\section{Study characteristics}

We searched the medical literature until 26 March 2015. This review includes one study with 117 participants in which a tooth (117 premolars) received a carbon fibre post, and was restored with either a fused porcelain to metal crown or a routine white filling. The study was of short duration (three years), included a relatively small number of participants, and was assessed to be at a high risk of bias due to missing results for people who dropped out of the study.

\section{Key results}

The evidence produced from one study concluded that none of the 117 root-filled premolars experienced a catastrophic failure (i.e. one that cannot be repaired) after three years, although only 104 teeth were included in the final, three-year assessment. The study concluded there was no difference between treatments for the risk of non-catastrophic failure. There was no evidence available for any of our secondary outcomes: patient satisfaction and quality of life, incidence or recurrence of decay, periodontal health status, and costs.

\section{Quality of the evidence}

The quality of the evidence is very low. As there is only a single study, which is at high risk of bias, there is insufficient reliable evidence to determine whether single crowns are better than routine fillings. Future research should aim to provide more reliable information that can help clinicians to decide on appropriate treatment whilst taking into consideration the individual circumstances and preferences of their patients. 
SUMMARY OF FINDINGS

\section{Summary of findings for the main comparison.}

Single crowns compared with conventional fillings for restoring root-filled teeth

Patient or population: people with a permanent tooth that has undergone endodontic treatment

Settings: private dental practice in Italy

Intervention: composite filling with post covered with full-coverage metal-ceramic crown (and oral hygiene instruction)

Comparison: composite filling with post (and oral hygiene instruction)

\begin{tabular}{|c|c|c|c|c|c|c|}
\hline \multirow[t]{3}{*}{ Outcomes } & \multicolumn{2}{|c|}{ Illustrative comparative risks* $(95 \% \mathrm{CI})$} & \multirow{3}{*}{$\begin{array}{l}\text { Relative effect } \\
(95 \% \mathrm{CI})\end{array}$} & \multirow{3}{*}{$\begin{array}{l}\text { No of Partici- } \\
\text { pants } \\
\text { (studies) }\end{array}$} & \multirow{3}{*}{$\begin{array}{l}\text { Quality of the evi- } \\
\text { dence } \\
\text { (GRADE) }\end{array}$} & \multirow[t]{3}{*}{ Comments } \\
\hline & Assumed risk & Corresponding risk & & & & \\
\hline & $\begin{array}{l}\text { Conventional fill- } \\
\text { ing }\end{array}$ & Single crown & & & & \\
\hline $\begin{array}{l}\text { Catastrophic failure of restora- } \\
\text { tion }\end{array}$ & 0 & 0 & & 117 & $\begin{array}{l}\oplus \ominus \ominus \ominus \\
\text { very low } 1\end{array}$ & \\
\hline $\begin{array}{l}\text { Non-catastrophic failure of the } \\
\text { restoration } \\
\text { (3 years) }\end{array}$ & 57 per 1000 & $\begin{array}{l}19 \text { per } 1000 \\
\text { ( } 3 \text { to } 174)\end{array}$ & $\begin{array}{l}\mathbf{R R} \mathbf{0 . 3 3}(0.04 \text { to } \\
3.05)\end{array}$ & 117 & $\begin{array}{l}\oplus \ominus \ominus \ominus \\
\text { very low } 1\end{array}$ & \\
\hline $\begin{array}{l}\text { Non-catastrophic failure of } \\
\text { post } \\
\text { (3 years) }\end{array}$ & 19 per 1000 & $\begin{array}{l}37 \text { per } 1000 \\
(4 \text { to } 400)\end{array}$ & $\begin{array}{l}\text { RR } 1.96 \text { (0.18 to } \\
21.01)\end{array}$ & 117 & $\begin{array}{l}\oplus \ominus \odot \odot \\
\text { very low } 1\end{array}$ & \\
\hline
\end{tabular}

*The basis for the assumed risk (e.g. the median control group risk across studies) is provided in footnotes. The corresponding risk (and its $95 \%$ confidence interval) is based on the assumed risk in the comparison group and the relative effect of the intervention (and its $95 \% \mathrm{Cl}$ ).

Cl: Confidence interval; RR: Risk Ratio

GRADE Working Group grades of evidence

High quality: Further research is very unlikely to change our confidence in the estimate of effect.

Moderate quality: Further research is likely to have an important impact on our confidence in the estimate of effect and may change the estimate.

Low quality: Further research is very likely to have an important impact on our confidence in the estimate of effect and is likely to change the estimate.

Very low quality: We are very uncertain about the estimate. 
Downgraded one level for limitations in study design (high risk of attrition bias), one level for imprecision (one small study with wide confidence intervals) and one level for indirectness. 2. From Additional Table 1 Proportion of non-catastrophic failures of the restoration (Mannocci 2002)

3. From Additional Table 2 Proportion of non-catastrophic failures of the post (Mannocci 2002) 


\section{B A C K G R O U N D}

\section{Description of the condition}

Root filling, or endodontic treatment, is a fairly routine dental procedure in which the dental pulp (nerve) is removed and replaced by a root canal filling. It is usually indicated when there has been irreversible inflammation or necrosis (death) of the pulp, consequent to caries or trauma (Heydecke 2002). Root filling and subsequent restoration represents a cost-effective option when it is compared with tooth extraction followed by implant placement (Pennington 2009).

However, the restoration of root-filled teeth can be quite challenging due to the structural differences between vital and nonvital root-filled teeth. Root canal preparation, prior to completion of the restoration, involves a process of accessing and shaping of the root canal that can ultimately lead to weakening of the tooth (Sornkul 1992). Dentin, the main constituent of dental roots, becomes more brittle after removal of the pulp (Gutmann 1992). Other noticeable changes that occur after root filling are those associated with the appearance of root-filled teeth. Altered light refraction and any remains of the pulp or filling material retained in the coronal portion of anterior teeth can cause darkening of the tooth (Cohen 2006).

\section{Description of the intervention}

Two methods, direct and indirect, can be used for the functional and aesthetic restoration of root-filled teeth.

The direct approach is through conventional techniques, in which the dentist places a restorative material such as amalgam or composite directly into the tooth. Conventional fillings usually need a single clinical appointment, are generally simpler to achieve than the indirect method, and have good survival characteristics (Bjertness 1990; Da Rosa Rodolpho 2006).

Indirect restorations (i.e. crowns) are fabricated with materials such as cast metal or ceramics (porcelain). According to their classical indication, single crowns can restore proportionately larger amounts of missing dentin and enamel than other approaches (Cohen 2006). However, the need for impressions and associated laboratory work to complete the final restoration may add considerably to the overall costs.

Regardless of the approach used, a post may also be required in the root canal to provide better retention for conventional fillings or crowns (Bolla 2007).

\section{How the intervention might work}

Root-filled teeth should be fully restored for a variety of reasons: to avoid recontamination of the root canal, to replace missing dental tissues (thus restoring function), and to strengthen the tooth (Vârlan 2009). The restoration of root-filled teeth by crowns can improve their ability to withstand bite forces, and thereby increase their survival (Aquilino 2002). However, such restorations demand the removal of a large amount of structure from teeth that are already compromised (Pierrisnard 2002). Conventional fillings may be clinically acceptable where there is sufficient tooth structure to retain the restorative material, or in situations where less destructive preparations are used in conjunction with adhesive restorations (Hemmings 2000). The preservation of healthy tooth structure is critical for the survival of conventional fillings. However, in the case of root-filled teeth, it has been reported that conventional composite fillings and crowns achieve the same success rate at three years (Mannocci 2002).

Current endodontic thinking proposes that there are four stages to root canal treatment: cleaning, shaping, obturation, and finally coronal restoration. A well adapted coronal restoration aims to prevent micro-leakage and subsequent bacterial ingress and contamination of the root canal complex. This would apply to either single crowns or conventional fillings so long as the reconstruction was classified as satisfactory in its ability to seal the crown of the tooth. A systematic review including 63 studies reported that periapical healing was improved by $10 \%$ to $18 \%$ when the quality of the coronal restoration was judged as satisfactory as opposed to unsatisfactory (Ng 2008).

The final outcome following coronal restoration after root canal treatment may only become apparent after a period of time. Rootfilled teeth covered with crowns have a greater long term survival rate $(81 \% \pm 12 \%$ after 10 years) than root-filled teeth without crown coverage (63\% $\pm 15 \%$ after 10 years; Stavropoulou 2007). For this reason, conventional direct resin fillings in root-filled teeth with limited loss of tooth structure have been also described as temporary restorations.

If this treatment concept is valid, then it is conceivable that every root-filled tooth could benefit from coverage with a crown.

\section{Why it is important to do this review}

The choice of restorative method for root-filled teeth is critical for the preservation of the remaining structure, and may influence long-term effectiveness. However, there is still uncertainty about the comparative clinical performance of crowns and conventional fillings used to restore root-filled teeth. The results of this review may better inform clinical decision making in the choice of either of these interventions for different clinical situations.

\section{OB JECTIVES}

To assess the effects of restoration of endodontically treated teeth (with or without post and core) by crowns versus conventional filling materials.

\section{METHODS}

\section{Criteria for considering studies for this review Types of studies}

Randomised controlled trials (RCTs) or quasi-randomised controlled trials. We considered parallel group trials, split-mouth trials, cluster trials and randomised patient preference trials.

\section{Types of participants}

Participants of any age or gender who had permanent teeth that had undergone endodontic treatment.

\section{Types of interventions}

Single full coverage indirect crowns (e.g. metal, metal-ceramic, and all-ceramic crowns) or other indirect partial restorations (e.g. inlays and onlays) compared with any type of filling materials for direct restoration (e.g. amalgam and composite). Trials that 
evaluated different types of bridge retainers were not considered for inclusion.

Comparisons were considered according to the type of post and core used (cast or prefabricated post), if any. We excluded studies with differences between groups regarding the types of posts used (e.g. crown on cast post versus direct restoration on no post).

\section{Types of outcome measures}

\section{Primary outcomes}

- Catastrophic failure of the restored tooth or restoration leading directly to extraction (to include the reasons for failure endodontic complications, restoration failure, tooth fracture).

- Non-catastrophic failure of the restoration requiring further treatment ${ }^{\star}$ categorised as i) failure of the restoration; ii) failure of the post.

\section{Secondary outcomes}

- Patient satisfaction and quality of life using any validated instrument.

- Incidence or recurrence of caries (assessed clinically or by radiographs).

- Periodontal health status.

- Costs for the use of different interventions (direct and indirect costs, e.g. the resources and time for the patient, dentist, and dental laboratory).

*Endpoints were analysed at the last follow-up time point, up to a period of 10 years after randomisation.

\section{Search methods for identification of studies}

\section{Electronic searches}

In conjunction with the Cochrane Oral Health Group's Trials Search Co-ordinator, we developed detailed search strategies for each database searched. These were based on the search strategy developed for MEDLINE (OVID) but revised appropriately for each database.

We searched the following databases, most recently in March 2015.

- MEDLINE via OVID (1948 to 26 March 2015) (Appendix 1)

- Cochrane Oral Health Group's Trials Register (Appendix 2) on 26 March 2015

- Cochrane Central Register of Controlled Trials (CENTRAL) (The Cochrane Library, 2012, Issue 1) (Appendix 3) on 26 March 2012

- EMBASE via OVID (1980 to 26 March 2015) (Appendix 4)

- CINAHL via EBSCO (1980 to 26 March 2015) (Appendix 5)

- LILACS via BIREME (1980 to 26 March 2015) (Appendix 6)

For the MEDLINE search, we ran the subject search with the Cochrane Highly Sensitive Search Strategy (CHSSS) for identifying randomised trials in MEDLINE: sensitivity maximising version (2008 revision), as referenced in Chapter 6.4.11.1 and detailed in box 6.4.c of the Cochrane Handbook for Systematic Reviews of Interventions version 5.1.0 (updated March 2011) (Higgins 2011). The search of EMBASE was linked to the Cochrane Oral Health Group filters for identifying randomised controlled trials, and the search of LILACS was linked to the Brazilian Cochrane Center filter.

\section{Ongoing trials}

Review author Zbys Fedorowicz (ZB) searched the following databases to March 2015, using keywords and terms expected to identify ongoing relevant trials.

- The metaRegister of Controlled Trials on http://www.controlledtrials.com/

- The US National Institutes of Health register on http:// www.clinicaltrials.gov/

- The WHO portal on http://who.int/ictrp/en/

\section{Language}

There were no language restrictions in the searches but we did not retrieve any studies that were not in the English language.

\section{Searching other resources}

In the original review, we examined the reference lists of relevant articles and contacted the investigators of included studies by electronic mail to ask for details of additional published and unpublished trials. One of the review authors (Patrick SequeiraByron (PSB)) handsearched the journals listed below, in accordance with the recommendations of the Cochrane Oral Health Group, up to March 2015.

- Caries Research (from 2003)

- Community Dentistry and Oral Epidemiology (from 2001)

- International Endodontic Journal (from 2005)

- International Journal of Prosthodontics (from 2003)

- Journal of Dental Research (from 2003)

- Journal of Endodontics (from 2007)

- Journal of Prosthetic Dentistry (from 2003)

\section{Data collection and analysis}

\section{Selection of studies}

In the update of this review, three authors (PSB, ZF, EA) independently assessed the abstracts of studies resulting from the searches; any disagreement between two authors on eligibility was resolved by a third review author.

In the original review, two review authors (PSB, ZF) independently assessed the abstracts of studies resulting from the searches. Full copies were obtained of all relevant and potentially relevant studies, i.e. those appearing to meet the inclusion criteria and those for which there were insufficient data in the title and abstract to make a clear decision. Two review authors independently assessed the full-text papers; any disagreement on eligibility was resolved through discussion and consensus or, if necessary, by a third review author. All irrelevant records were excluded; the details and the reasons for their exclusion are noted in the Characteristics of excluded studies section of the review.

\section{Data extraction and management}

ZF entered study details into the Characteristics of included studies tables in RevMan 5.1 (RevMan 2014). Two review authors (Ben Carter (BC), ZF) independently extracted data in duplicate, and only included them if there was a consensus; any disagreements were resolved by consulting with a third review author (Raphael Freitas de Souza (RFS)). 
The following details were extracted if reported.

1. Trial methods: (a) method of allocation; (b) masking of participants, trialists and outcome assessors; (c) exclusion of participants after randomisation and proportion, and reasons for losses at follow-up.

2. Participants: (a) country of origin and study setting; (b) sample size; (c) age; (d) gender; (e) inclusion and exclusion criteria; (f) caries risk status of study groups; (g) characteristics of the restored teeth such as type and location in the mouth, and the state of remaining structures; (h) salivary flow; (i) periodontal status; (j) presence and intensity of parafunction (i.e. bruxism); (k) materials and techniques used for root filling; (l) time from root filling to restoration.

3. Intervention: (a) type of restoration; (b) materials and techniques used; (c) type of post and core used, if any; (d) time of follow-up.

4. Control: (a) type of restoration; (b) materials and techniques used; (c) type of post and core used, if any; (d) time of follow-up.

5. Outcomes: (a) primary and secondary outcomes mentioned in the Types of outcome measures section of this review.

If stated, the sources of funding were recorded. If a sufficient number of studies assessing similar interventions are identified for inclusion in future updates of this review, we will use information of source of funding to help to assess heterogeneity and the external validity of any included trials.

\section{Assessment of risk of bias in included studies}

Two review authors (Mona Nasser (MN), ZF) independently assessed risk of bias in the selected trials using The Cochrane Collaboration's tool for assessing risk of bias as described in section 8.5 of the Cochrane Handbook for Systematic Reviews of Interventions (Higgins 2011). The judgments were compared and any inconsistencies in the assessments between the review authors were discussed and resolved.

The following domains were assessed as at a low, high or unclear risk of bias:

1. sequence generation (selection bias);

2. allocation concealment (selection bias);

3. blinding of participants and personnel (performance bias);

4. blinding of outcome assessors (detection bias);

5. incomplete outcome data (attrition bias);

6. selective outcome reporting (reporting bias);

7. other bias.

We categorised and reported the overall risk of bias of the included study according to the following:

- low risk of bias (plausible bias unlikely to seriously alter the results) if all domains were assessed as at a low risk of bias;

- unclear risk of bias (plausible bias that raises some doubt about the results) if one or more domains were assessed as at an unclear risk of bias; or

- high risk of bias (plausible bias that seriously weakens confidence in the results) if one or more domains were assessed as at a high risk of bias.

\section{Measures of treatment effect}

We carried out data analysis using the 'treatment as allocated' patient population. For dichotomous data, we expressed the estimates of effect of an intervention as risk ratios (RR) together with their $95 \%$ confidence intervals ( $\mathrm{Cl}$ ). Although neither time-toevent or continuous data were reported, in future updates, if data are available, these effect measures will be used to summarise the data for each group accordingly. For continuous outcomes, we will present mean differences and their $95 \%$ confidence intervals; timeto-event data will be evaluated based on hazard ratios. If summary statistics are not available from the reports, we will attempt to calculate hazard ratios by means of other statistics and survival curves (Parmar 1998).

\section{Unit of analysis issues}

Although no cluster-randomised trials were identified, these would have been checked for unit of analysis errors based on the advice provided in section 16.3.4 of the Cochrane Handbook for Systematic Reviews of Interventions (Higgins 2011).

\section{Dealing with missing data}

In studies where data were unclear or missing, we contacted the principal investigators. If missing data were unavailable, we would have followed the advice given in section 16.1.2 of the Cochrane Handbook for Systematic Reviews of Interventions (Higgins 2011), and if appropriate, sensitivity analyses would have been carried out to input the missing data:

- best-worst case scenario: which is the best scenario for the composite + crown and worst scenario for the composite only group

- worst-best case scenario: which is the best scenario for the composite-only group and worst scenario for the composite + crown group.

As only one study was included, we did not undertake these sensitivity analyses but will do so in future updates if more studies are available.

\section{Assessment of heterogeneity}

The paucity of studies included in this review did not permit any assessment of heterogeneity but in future updates if further studies are included, the following methods will apply. We will assess clinical heterogeneity by examining the characteristics of the studies, the similarity between the types of participants, the interventions and the outcomes as specified in the criteria for included studies. We will assess statistical heterogeneity using a $\mathrm{Chi}^{2}$ test and the $\mathrm{I}^{2}$ statistic. The $\mathrm{I}^{2}$ values expressed as percentages will be categorised as follows: $25 \%$ as low, $50 \%$ as moderate, and $75 \%$ as high (Higgins 2003).

\section{Assessment of reporting biases}

If a sufficient number of studies assessing similar interventions are identified for inclusion in future updates of this review, we will assess publication bias according to the recommendations on testing for funnel plot asymmetry as described in section 10.4.3.1 of the Cochrane Handbook for Systematic Reviews of Interventions (Higgins 2011). If asymmetry is identified, we will attempt to assess other possible causes, and explore these in the discussion if appropriate. 


\section{Data synthesis}

If future updates include a sufficient number studies (more than two) investigating similar interventions, we will conduct data analysis in RevMan (RevMan 2014), and the following methods will apply. We will use the fixed-effect model if appropriate. If there is heterogeneity between the studies, we will undertake a random-effects meta-analysis, but if the heterogeneity between the studies is significant, we will explore the data to explain why, and may not undertake a meta-analysis at all (see section 9.5 of the Cochrane Handbook for Systematic Reviews of Interventions 5.1.0 (Higgins 2011)). If sufficient data are available, we will calculate a pooled estimate of effect of specific interventions together with their corresponding 95\% confidence intervals $(\mathrm{Cl})$.

\section{Subgroup analysis and investigation of heterogeneity}

If a sufficient number of studies are included in any update of this review, and we identify moderate, substantial or considerable heterogeneity (see Assessment of heterogeneity), we plan to carry out the following subgroup analyses according to: the type of post and core used for retention in the root canal (cast posts, preformed posts or none); the type of restored tooth; the location in the oral cavity: anterior and posterior teeth (categorised into bicuspids and molars); and the type of crown (metal-ceramic, all metallic or all ceramic crown).

\section{Sensitivity analysis}

We had planned to carry out sensitivity analyses to assess the robustness of our review results, in particular, to repeat the analyses excluding studies with a high risk of bias (Egger 1997). If future studies report the reasons for failure, we will carry out further sensitivity analyses to assess each of the reasons for failure, i.e. marginal failure, wear, presence of fractures.

\section{Summarising the findings}

We created a 'Summary of findings' table for the primary outcomes of this review following GRADE methods (GRADE 2004) and using GRADEPro software (GRADEpro 2008). To assess the quality of the body of evidence as high, moderate, low or very low, we considered the overall risk of bias of the included studies, the directness of the evidence, the consistency of the results, the precision of the estimates, and the risk of publication bias.

\section{RE S U L T S}

\section{Description of studies}

\section{Results of the search}

The original electronic searches in 2012 retrieved 1022 references to studies after de-duplication, out of which, 1016 were clearly ineligible and were eliminated. We obtained full-text copies of the remaining six studies and subjected them to further evaluation. We excluded all but one of these studies.

Through handsearching, we did not retrieve any additional studies over and above those that had already been identified in the electronic search, therefore, we did not re-run these searches for this update. No studies in languages other than English were identified and our searches of the trial registries did not identify any ongoing trials. We also examined several other reviews for potentially eligible studies but did not find any. No cluster-randomised trials (i.e. groups of individuals randomised to intervention or control), were identified for inclusion in this review.

The updated searches to 26 March 2015 retrieved 279 references to studies, all of which were rejected after examination of title and abstract.

For further details, see Figure 1. 
Figure 1. Study flow diagram

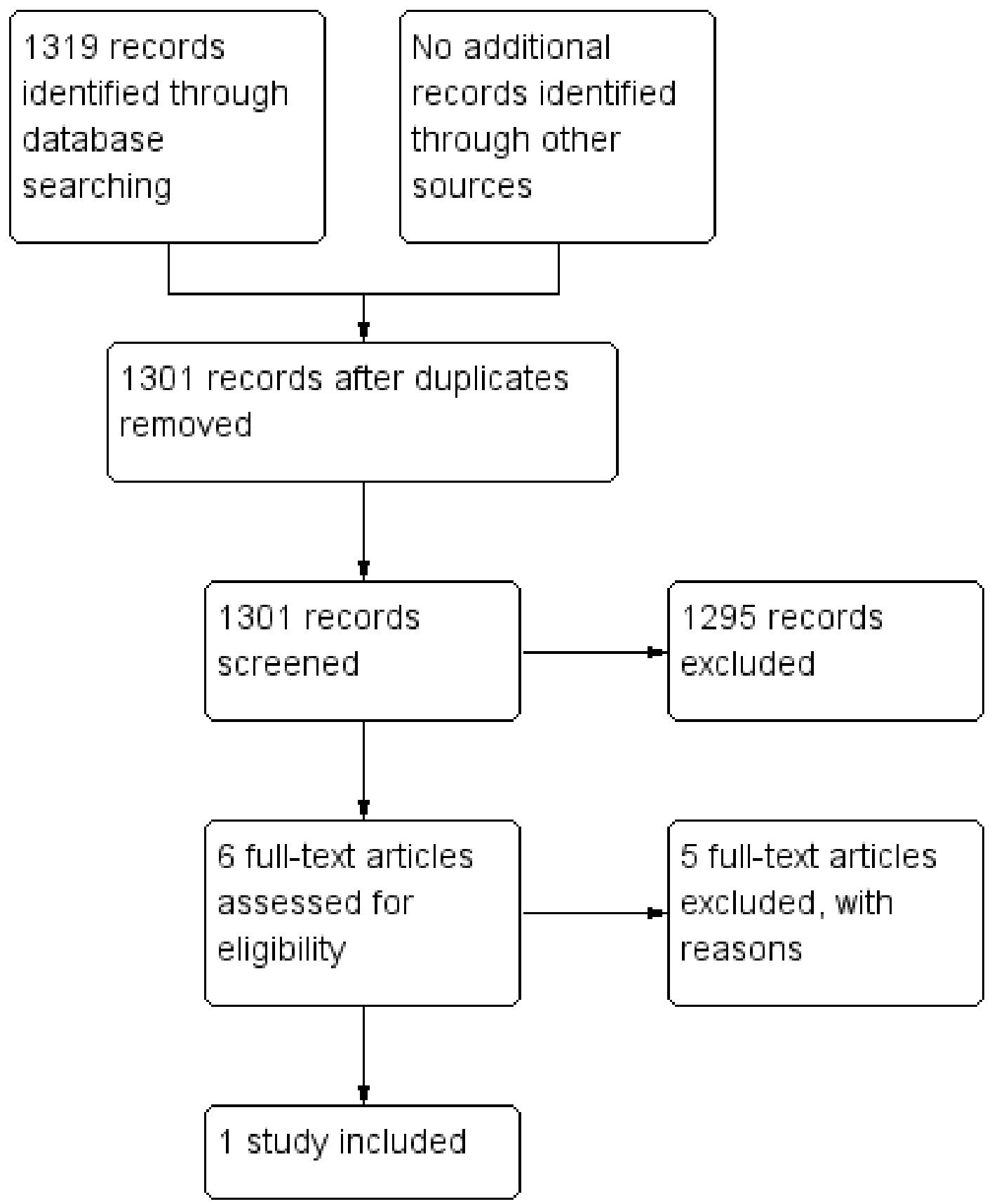

\section{Included studies}

A single study is included in this review (Mannocci 2002).

\section{Characteristics of the trial setting and investigators}

This study was a randomised controlled trial of three years duration. It was conducted in a private practice setting in Italy. One investigator based in a single clinic carried out all the treatment.

\section{Characteristics of the participants}

A total of 117 (54 male, 63 female) participants with an age range of 35 to 55 (mean 48) years were enrolled in this study. Each participant provided a single premolar tooth to include 24 maxillary first premolars, 57 maxillary second premolars, 3 first, and 33 mandibular second premolars that required orthograde endodontic treatment. The teeth had Class II carious lesions that did not involve the cusps; had no more than $40 \%$ loss in periodontal attachment; were in occlusal function after restoration; and were not used as abutments for fixed or removable partial dentures.

\section{Characteristics of the interventions}

A single operator carried out the orthograde endodontic treatment and the final restoration of the tooth. The root canal was obturated with gutta percha and then received a carbon fibre post (Composipost; RTD, St Egreve, France ${ }^{\circledR}$ ), which was cemented in the canal with composite (C\&B; BISCO, Itasca, Ill., USA $\left.{ }^{\circledR}\right)$. The 
teeth were then restored with a composite material using an adhesive technique (60 participants) or had a composite core and build-up (Z100; 3M, St Paul, Minn., USA $\left.{ }^{\circledR}\right)$, and were subsequently prepared for full-coverage metal-ceramic crowns according to standard clinical procedures (57 participants). All participants received routine oral hygiene instruction, which was provided by a dental hygienist at subsequent follow-up visits.

\section{Characteristics of the outcomes measures}

Clinical, radiographic, and photographic assessments of outcomes were carried out by two calibrated examiners, neither of whom were investigators, at several time points: immediately before restoration, immediately after restoration, and at one-, two-, and three-year recall. The principal outcomes assessed were the success or failure of the restoration. Failures were categorised as root fracture, post fracture, post decementation, clinical or radiographic evidence of a marginal gap between tooth and restoration, or the presence of secondary caries at the margins of the restoration.

\section{Excluded studies}

A list of the five studies excluded from this review and the reasons for their exclusion are reported in the Characteristics of excluded studies table.

\section{Risk of bias in included studies}

Details of these assessments are available in the relevant section of the Characteristics of included studies table, and are also presented in the 'Risk of bias' summary (Figure 2). The summary assessment of risk of bias for the single study included in this review was high risk (plausible bias that seriously weakens confidence in the results), because of incomplete outcome data.

\section{Figure 2. Risk of bias summary: review authors' judgements about each risk of bias item for each included study}

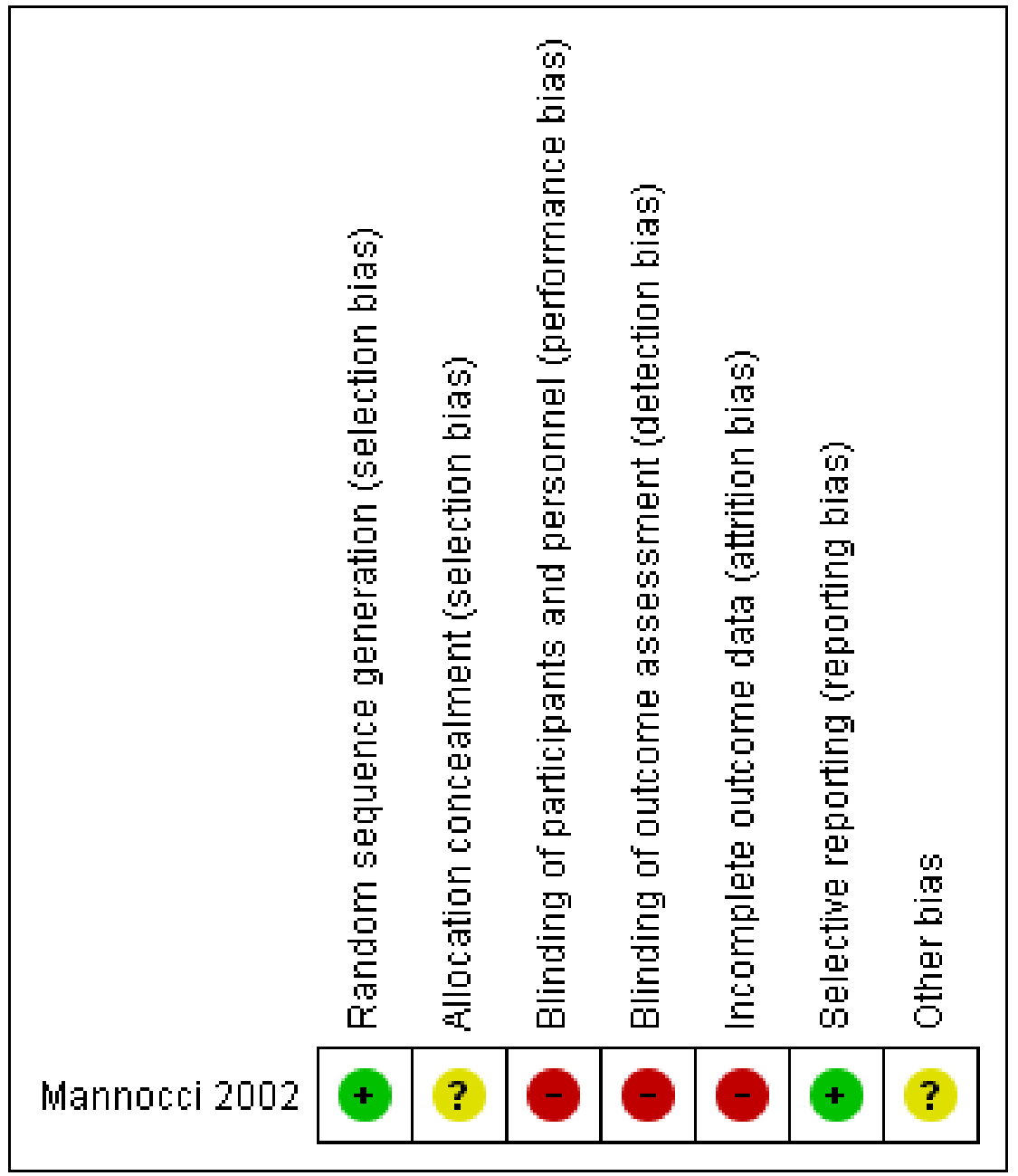

\section{Allocation}

The investigators randomised participants to interventions with the toss of a coin and therefore, the sequence generation was judged as being at a low risk of bias. However, as they did not report the method used to conceal the allocation sequence, the study was assessed as being at unclear risk of selection bias.
Blinding

\section{Blinding of participants and personnel}

The type of interventions considered in this study did not permit blinding of the participants or the trial investigators, which made it at a high risk of performance bias. 


\section{Blinding of outcome assessors}

Neither the participants nor the investigators were the assessors for the study outcomes. Outcomes were assessed by two independent calibrated examiners but they were not blinded so we assessed the risk of detection bias as high.

\section{Incomplete outcome data}

Five out of 60 participants in the composite-only group were lost to follow-up at the one-year recall. At the two-year recall, $12 / 60$ of the participants in the composite-only group did not attend for follow-up; the report was unclear if these included the five participants lost at the one-year recall. At the threeyear recall, 10/60 (composite only) and 3/57 (composite and crown) participants were unavailable for assessment. The report did not provide sufficient information on the final disposition of these missing participants and their corresponding outcome data; therefore the study was judged to be at high risk of attrition bias.

\section{Selective reporting}

Although the data provided by the investigators were sparse, the published report included all expected outcomes, including those that were prespecified in the trial's methods section. Therefore, we gave a judgement of low risk of reporting bias.

\section{Other potential sources of bias}

Baseline measurements of caries, periodontal and endodontic outcomes were not measured, so we judged this domain as an unclear risk of bias.

\section{Effects of interventions}

See: Summary of findings for the main comparison

Two review authors (BC, ZF) analysed the data and reported them as specified in Chapter 9 of the Cochrane Handbook for Systematic Reviews of Interventions 5.1.0 (Higgins 2011).

\section{Primary outcomes}

\section{Catastrophic failure of the restored tooth or restoration leading directly to extraction}

No teeth were reported to have been lost as a result of trauma or endodontic or periodontal problems over the three-year study period, but because of the large losses to follow-up, the data were incomplete and it was not possible to confirm the validity of these findings.

\section{Non-catastrophic failure of the restoration requiring further treatment}

a) Failure of the restoration (marginal fit, wear, presence of fractures)

Failures of the restoration occurring during each of the three years of the study are reported in Additional Table 1 and the analysis of restoration failure in Analysis 1.1. There was one failure in the composite and crown group (out of 54 participants) and three in the composite-only group (out of 53 participants) by the end of the study; the risk ratio (RR) was 0.33 ( $95 \%$ confidence interval $(\mathrm{Cl}) 0.04$ to $3.05 ; \mathrm{P}$ value $=0.33$ ). Restoration failure, as an outcome over the three-year study period, should be viewed as unclear.

\section{b) Post failure}

The post failures occurring during each of the three years of the study are reported in Additional Table 2 and the analysis of post failure across the three years in Analysis 1.2. At the end of the study period, there were two post failures (from 54 participants) in the composite and crown group and one (from 53 participants) in the composite-only group; the RR was $1.96(95 \% \mathrm{Cl} 0.18$ to 21.01 , $P$ value $=0.58)$. Therefore, there was no evidence to indicate a difference in post failure rate between the two intervention groups; however, in view of the considerable amount of missing data, these results should be viewed as inconclusive.

\section{Secondary outcomes}

\section{Patient satisfaction and quality of life using any validated instrument}

This outcome was not reported nor measured by the study.

\section{Incidence or recurrence of caries (assessed clinically or by radiographs)}

No data were reported nor measured by the study.

\section{Periodontal health status}

No data were reported nor measured by the study.

4. Costs for the use of different treatment interventions (direct and indirect costs e.g. resources and time for the patient, dentist, and dental laboratory)

No data were reported nor measured by the study.

\section{DISCUSSION}

\section{Summary of main results}

None of the trial's 117 participants, each with a root-filled, premolar tooth restored with a carbon fibre post and either a full coverage metal-ceramic crown or a direct adhesive composite restoration experienced a catastrophic failure of the restoration. The trial concluded that at three years there was no difference between groups in the non-catastrophic failure rates. Decementation of the post and marginal gap formation occurred in a small number of teeth. However, in view of missing outcome data, this trial was assessed to be at a high risk of bias and therefore, caution is advised in the interpretation of these results.

\section{Overall completeness and applicability of evidence}

This study was completed 13 years ago; although the investigators indicated that they planned to continue the study for an additional three years, there would appear to have been no follow-up or indeed, any further randomised clinical trials investigating these comparisons. The single trial met the eligibility criteria for inclusion; however, the restrictions placed on enrolment of teeth with moderately sized carious lesions with no cuspal involvement may have contributed to an element of selection bias. Additional factors to consider were that only premolar teeth, which are more likely to have proportionately less salvageable tooth structure than molars, were included in the study. And although posts, which some clinicians consider can reinforce a restoration or in some instances might weaken a tooth root, were integral to the restoration of these premolars, this may be at variance with their clinical applicability in the restoration of some molar teeth. It also 
remains unclear to what extent this evidence, based on somewhat older materials, may be applicable to the types of new materials currently at the disposal of clinicians.

Consequently, the included study may have addressed a restricted version of the review question in terms of the 'population' under investigation and the interventions used.

\section{Quality of the evidence}

\section{Limitations in study design}

There were challenges in the design of this study due to the inability to satisfactorily blind investigators and outcomes assessors to the interventions, which is considered a valuable step in reducing bias. In addition, a clearer definition of survival and in particular, noncatastrophic failure of the restorations, would have helped to limit the effects of subjectivity in the assessment of these outcomes. Missing data for losses to follow-up and the final disposition of missing participants, in a study where failure was a key outcome, were additional indicators of a high likelihood of biased assessment of the intervention effect. Overall, therefore, the included study was at high risk of performance, detection and attrition bias.

\section{Inconsistency}

Only one trial provided data in this review, therefore this assessment was not applicable.

\section{Indirectness of evidence}

The report provided minimal demographic details of the participants, in particular those relating to their caries-risk status, so it is difficult to assess if they are representative of the population at large. Some of these variables (such as caries prevalence and incidence, as well as periodontal, endodontic and prosthetic risk factors) represent potentially key factors in the survival and longevity of either restorative procedure, and may ultimately have an impact on the directness and applicability of the results of the review.

Significant loss of tooth structure is an indicator of the clinical necessity for a post and core to restore endodontically treated teeth. However, whilst all of the premolar teeth in this study received a post, the criteria for post requirement were inadequately defined, and it remains unclear how these might apply to other clinical situations, i.e. molar teeth, which are likely to have proportionately more residual coronal tooth structure.

\section{Imprecision}

The main objective of the single study included in this review was to investigate the comparative success or failure of two interventions; however, to adequately power such an equivalence (or noninferiority) study, a substantially larger number of participants and a longer follow-up period would normally be required. Thus, although the investigators concluded that there was no difference in failure rate between the two interventions, in view of the absence of a sample-size calculation, there is a degree of uncertainty if the study included a sufficiently large enough number of participants to detect a modest and statistically significant difference, if indeed there was one.

\section{Publication bias}

Every effort was made to identify additional published studies. Only one trial was included and therefore, it was not possible to undertake a funnel plot assessment of publication bias (Higgins 2011).

These criticisms were summarised in terms of an overall GRADE quality rating per outcome. We downgraded once for study design, once for imprecision, and once for indirectness, i.e. very low quality overall.

\section{Potential biases in the review process}

Although bias can never be totally eliminated, the comprehensive search for studies, and the authors' independent assessments of eligibility of studies for inclusion in this review and the extraction of data, minimised the potential for bias in the review process.

\section{Agreements and disagreements with other studies or reviews}

We are unaware of any recent systematic reviews on this topic but there have been several recent mini reviews and evidencebased summaries (Basrani 2004; Evidence-Based Review 2009), which largely agree with the conclusions in this systematic review that there is no clear evidence of a difference, but the available evidence is of very low quality. This is in contrast to an earlier retrospective analysis of a random sample of the dental charts of 280 patients who had undergone endodontic treatment, which reported that when tooth type and radiographic evidence of caries were controlled, root-filled teeth that were not crowned were lost at a six times greater rate than teeth crowned after obturation (Aquilino 2002). The results of this retrospective study, whilst providing valuable information on a range of clinical variables, do not constitute reliable, high quality evidence for the effects of the interventions considered in this review.

\section{AUTHORS' CONCLUSIONS}

\section{Implications for practice}

The single study of 117 participants included in this review was judged to be at high risk of performance, detection and attrition bias. Therefore, there is insufficient reliable evidence from this review to determine whether a conventional filling, such as composite material, is more effective than full coronal coverage for the restoration of root-filled premolar teeth with sufficient coronal tooth structure.

\section{Implications for research}

There is limited evidence of the effectiveness or benefit of single crowns over conventional fillings. Further research may be justified to investigate the relative effects of: differing loss of tooth structure when restoring endodontically treated teeth; the enrolment of participants with high and low caries-risk; and the provision of care in different settings. Consideration should also be given to examining the effect of patients' preferences and expectations of outcomes, and the inclusion of a formal cost effectiveness analysis across the two treatment options. The importance of valid, reliable and reproducible assessments of survival and failure should not be underestimated, therefore, greater attention should be given to the use of criteria based on the US Public Health Service (USPHS) 
evaluation methods (Bayne 2005) in an assessment of the in-service performance of these restorative techniques and materials.

Future randomised controlled trials must be well designed, well conducted and adequately delivered with subsequent reporting, including high quality descriptions of all aspects of methodology. Rigorous reporting needs to conform to the Consolidated Standards of Reporting Trials (CONSORT) statement (CONSORT 2010), which will enable appraisal and interpretation of results, and accurate judgements to be made about the risk of bias and the overall quality of the evidence. Although it is uncertain whether reported quality mirrors actual study conduct, it is noteworthy that studies with unclear methodology have been shown to produce biased estimates of treatment effects (Schulz 1995). Adherence to guidelines, such as the CONSORT statement, would help to ensure complete reporting.

For further research recommendations based on the EPICOT format (Brown 2006), see Additional Table 3.

\section{ACKN OWLEDGEMENTS}

The review authors would like to thank the Cochrane Oral Health Group and the peer referees for their help in conducting the original systematic review. We would like to thank Anne-Marie Glenny, Susan Furness and Laura MacDonald for help with the update.

We would like to acknowledge the contribution of Raphael Freitas de Souza and Carolina de Andrade Lima Chaves as authors on the original review. 


\section{REFERE N CE S}

\section{References to studies included in this review}

Mannocci 2002 \{published data only\}

Mannocci F, Bertelli E, Sherriff M, Watson TF, Ford TR. Threeyear clinical comparison of survival of endodontically treated teeth restored with either full cast coverage or with direct composite restoration. Journal of Prosthetic Dentistry 2002;88(3):297-301.

\section{References to studies excluded from this review}

Basrani 2004 \{published data only\}

Basrani B, Matthews D. Survival rates similar with full cast crowns and direct composite restorations. Evidence-Based Dentistry 2004;5(2):45.

\section{Bitter 2010 \{published data only\}}

Bitter K, Meyer-Lueckel H, Fotiadis N, Blunck U, Neumann K, Kielbassa AM, et al. Influence of endodontic treatment, post insertion, and ceramic restoration on the fracture resistance of maxillary premolars. International Endodontic Journal 2010;43(6):469-77.

\section{Fokkinga 2007 \{published data only\}}

Fokkinga WA, Kreulen CM, Bronkhorst EM, Creugers NHJ. Up to 17-year controlled clinical study on post-and-cores and covering crowns. Journal of Dentistry 2007;35(10):778-86.

\section{Fokkinga 2008 \{published data only\}}

Fokkinga WA, Kreulen CM, Bronkhorst EM, Creugers NH. Composite resin core-crown reconstructions: an up to 17-year follow-up of a controlled clinical trial. International Journal of Prosthodontics 2008;21(2):109-15.

\section{Mannocci 2003 \{published data only\}}

Mannocci F, Bertelli E, Watson TF, Ford TP. Resin-dentin interfaces of endodontically-treated restored teeth. American Journal of Dentistry 2003;16(1):28-32.

\section{Additional references}

\section{Aquilino 2002}

Aquilino SA, Caplan DJ. Relationship between crown placement and the survival of endodontically treated teeth. Journal of Prosthetic Dentistry 2002;87(3):256-63.

\section{Bayne 2005}

Bayne SC, Schmalz G. Reprinting the classic article on USPHS evaluation methods for measuring the clinical research performance of restorative materials. Clinical Oral Investigations 2005;9(4):209-14.

\section{Bjertness 1990}

Bjertness E, Sønju T. Survival analysis of amalgam restorations in long-term recall patients. Acta Odontologica Scandinavica 1990;48(2):93-7.

\section{Bolla 2007}

Bolla M, Muller-Bolla M, Borg C, Lupi-Pegurier L, Laplanche O, Leforestier E. Root canal posts for the restoration of root filled teeth. Cochrane Database of Systematic Reviews 2007, Issue 1. [DOI: 10.1002/14651858.CD004623.pub2]

\section{Brown 2006}

Brown P, Brunnhuber K, Chalkidou K, Chalmers I, Clarke M, Fenton $\mathrm{M}$, et al. How to formulate research questions. BMJ 2006;333(7572):804-6.

\section{Cohen 2006}

Cohen S, Hargreaves KM. Pathways of the Pulp. 9th Edition. St Louis: Mosby, 2006.

\section{CONSORT 2010}

Schulz KF, Altman DG, Moher D, for the CONSORT Group. CONSORT 2010 Statement: updated guidelines for reporting parallel group randomised trials. Trials 2010, 11:32. (24 March 2010). http://www.consort-statement.org/consort-2010 (accessed 10 August 2015).

\section{Da Rosa Rodolpho 2006}

Da Rosa Rodolpho PA, Cenci MS, Donassollo TA, Loguércio AD, Demarco FF. A clinical evaluation of posterior composite restorations: 17-year findings. Journal of Dentistry 2006;34(7):427-35.

\section{Egger 1997}

Egger M, Davey Smith G, Schneider M, Minder C. Bias in meta-analysis detected by a simple, graphical test. $B M J$ 1997;315(7109):629-34.

\section{Evidence-Based Review 2009}

Evidence-Based Review of Clinical Studies on Restorative Dentistry. Journal of Endodontics 2009; Vol. 35, issue 8:1111-5.

\section{Gutmann 1992}

Gutmann JL. The dentin-root complex: anatomic and biologic considerations in restoring endodontically treated teeth. Journal of Prosthetic Dentistry 1992;67(4):458-67.

\section{Hemmings 2000}

Hemmings KW, Darbar UR, Vaughan S. Tooth wear treated with direct composite restorations at an increased vertical dimension: results at 30 months. Journal of Prosthetic Dentistry 2000;83(3):287-93

\section{Heydecke 2002}

Heydecke G, Peters MC. The restoration of endodontically treated, single-rooted teeth with cast or direct posts and cores: a systematic review. Journal of Prosthetic Dentistry 2002;87(4):380-6.

\section{Higgins 2003}

Higgins JP, Thompson SG, Deeks JJ, Altman DG. Measuring inconsistency in meta-analyses. BMJ 2003;327(7414):557-60. 


\section{Higgins 2011}

Higgins JPT, Green S (editors). Cochrane Handbook for Systematic Reviews of Interventions version 5.1.0 (updated March 2011). The Cochrane Collaboration, 2011. Available from www.cochrane-handbook.org.

\section{Loe 1963}

Loe $\mathrm{H}$, Silness J. Periodontal disease in pregnancy. 1. Prevalence and severity. Acta Odontologica Scandinavica 1963;21:533-51.

\section{$\mathrm{Ng} 2008$}

$\mathrm{Ng}$ YL, Mann V, Rahbaran S, Lewsey J, Gulabivala K. Outcome of primary root canal treatment: systematic review of the literature -- Part 2. influence of clinical factors. International Endodontic Journal 2008;41(1):6-31.

\section{Parmar 1998}

Parmar MK, Torri V, Stewart L. Extracting summary statistics to perform meta-analyses of the published literature for survival endpoints. Statistics in Medicine 1998;17(24):2815-34.

\section{Pennington 2009}

Pennington MW, Vernazza CR, Shackley P, Armstrong NT, Whitworth JM, Steele JG. Evaluation of the cost-effectiveness of root canal treatment using conventional approaches versus replacement with an implant. International Endodontic Journal 2009;42(10):874-83.

\section{Pierrisnard 2002}

Pierrisnard L, Bohin F, Renault P, Barquins M. Coronoradicular reconstruction of pulpless teeth: a mechanical study

\section{CHARACTERISTICS OF STUDIES}

Characteristics of included studies [ordered by study ID] using finite element analysis. Journal of Prosthetic Dentistry 2002;88(4):442-8.

\section{RevMan 2014 [Computer program]}

The Nordic Cochrane Centre, The Cochrane Collaboration. Review Manager (RevMan). Version 5.3. Copenhagen: The Nordic Cochrane Centre, The Cochrane Collaboration, 2014.

\section{Schulz 1995}

Schulz KF, Chalmers I, Hayes RJ, Altman DG. Empirical evidence of bias. Dimensions of methodological quality associated with estimates of treatment effects in controlled trials. JAMA 1995;273(5):408-12.

\section{Sornkul 1992}

Sornkul E, Stannard JG. Strength of roots before and after endodontic treatment and restoration. Journal of Endodontics 1992;18(9):440-3.

\section{Stavropoulou 2007}

Stavropoulou AF, Koidis PT. A systematic review of single crowns on endodontically treated teeth. Journal of Dentistry 2007;35(10):761-7.

\section{Vârlan 2009}

Vârlan C, Dimitriu B, Vârlan V, Bodnar D, Suciu I. Current opinions concerning the restoration of endodontically treated teeth: basic principles. Journal of Medicine and Life 2009;2(2):165-72.

\section{Mannocci 2002}

Methods Randomised controlled trial, setting and start date unspecified, 3-year duration. The setting was confirmed following telephone communication with the principal investigator as a single private practice and that the study participants were enrolled between 1997 and 1998.

Participants

Inclusion criteria:

- Single maxillary or mandibular premolar requiring endodontic treatment and crown build up

- Class II carious lesions without previous endodontic treatment and with preserved cusp structure

- In occlusal function after restoration

- Not used as abutment for fixed or removable partial dentures

- Loss of periodontal attachment (<40\%), assessed using the gingival index score (Loe 1963)

Exclusion criteria:

- Spontaneous gingival bleeding (gingival index score $=3$ )

Randomised: 117 (54 male, 63 female). Age range 35 to 55 years (mean 48 years)

Teeth: maxillary first premolars (24), maxillary second premolars (57), first (3) and second (33) mandibular premolars

Withdrawals/losses to follow-up:

Losses at specific recall time points: 
Mannocci 2002 (Continued)

- 1 year recall 5/60 (composite only)

- 2 year recall 12/60 (composite only)

- 3 year recall 10/60 (composite only) and 3/57 (composite and crown)

Interventions

Intervention: Group 1: orthograde endodontic treatment including a carbon fibre post, restored with adhesive techniques and composite (60 teeth)

Comparison: Group 2: orthograde endodontic treatment including a carbon fibre post, restored with adhesive techniques and composite, and covered with full-coverage metal-ceramic crown (57 teeth) Composite restoration and core and crown build-up identical for both groups (Light polymerising composite Z100, 3M). Crown preparation, impression, temporising and cementation according to standard clinical techniques

All restorations carried out by a single operator

Routine oral hygiene instruction from a dental hygienist

Outcomes

Clinical, radiographic and photographic evaluation by two calibrated examiners (not investigators); immediately before and after restoration and at 1, 2, 3 year recall.

Outcomes: (as reported)

1. Failure i.e. root fracture, post fracture, post decementation*

2. Clinical and/or radiographic evidence of a marginal gap between tooth and restoration*

3. Clinical evidence of secondary caries contiguous with the margins of the restoration*

Clinical assessment: margins of the restoration with explorer and loops with fibreoptic illumination

Photographic assessment: colour slides of the restorations with standard film

Periapical radiographic assessment: standard paralleling technique

Definition of failure:

- marginal gap between tooth and restoration determined by explorer

- radiographic evidence of a marginal gap between tooth and restoration

- secondary caries at the restoration margin, after the removal of the restoration

- root fracture noted after tooth extraction

- post fracture separation into two post parts

- post decementation separation of the post-core (crown) restoration from tooth structure

*Denotes outcomes prespecified in this review.

Notes

Risk of bias

Bias Authors' judgement Support for judgement

Random sequence genera- Low risk Quote: "selected subjects were randomly assigned to 1 of the following 2 ex tion (selection bias) perimental groups by tossing a coin" Page 298

Comment: probably done

\begin{tabular}{|c|c|c|}
\hline $\begin{array}{l}\text { Allocation concealment } \\
\text { (selection bias) }\end{array}$ & Unclear risk & $\begin{array}{l}\text { The method used to conceal the allocation sequence, that is to determine } \\
\text { whether intervention allocations could have been foreseen in advance of, or } \\
\text { during enrolment, was not reported } \\
\text { Comment: insufficient information to permit a clear judgement. }\end{array}$ \\
\hline
\end{tabular}


Telephone contact with principal investigator: no further information provided to enable any change to this assessment

\begin{tabular}{|c|c|c|}
\hline $\begin{array}{l}\text { Blinding of participants } \\
\text { and personnel (perfor- } \\
\text { mance bias) } \\
\text { All outcomes }\end{array}$ & High risk & $\begin{array}{l}\text { The nature of the interventions makes blinding of the participants or the trial } \\
\text { investigators difficult, however no attempt was made to avoid performance } \\
\text { bias. }\end{array}$ \\
\hline
\end{tabular}

Blinding of outcome as-
sessment (detection bias)
sessment (detection bias) All outcomes

Quote: "Evaluation of success or failure was performed by 2 examiners other than the operator" Page 300.

Comment: the outcome assessors were not the care providers. They were calibrated and inter-rater agreement for the specified outcomes was $>90 \%$.

Comment: As they were not blinded this presents a high risk of assessment bias.

Incomplete outcome data High risk
(attrition bias)

All outcomes

Participants not available at the 2 and 3 year recall were reported but no reasons given

Losses to follow-up were not balanced across groups; and were large (> 20\%) and not consistent at both recall time points in the composite-only group

Comment: although it was unclear from the report if these data were missing at random, this domain was judged as at a high risk of bias.

\begin{tabular}{lll}
\hline $\begin{array}{l}\text { Selective reporting (re- } \\
\text { porting bias) }\end{array}$ & Low risk & $\begin{array}{l}\text { Although data were sparse, all expected and prespecified outcomes appear to } \\
\text { have been reported }\end{array}$ \\
\hline Other bias & Unclear risk & $\begin{array}{l}\text { Baseline measurements of caries, periodontal and endodontic outcomes were } \\
\text { not reported. This presents an unclear risk of other bias (e.g. severity of illness } \\
\text { bias) }\end{array}$ \\
\hline
\end{tabular}

Characteristics of excluded studies [ordered by study ID]

\begin{tabular}{ll}
\hline Study & Reason for exclusion \\
\hline Basrani 2004 & Evidence-based summary of Mannocci 2002 \\
\hline Bitter 2010 & $\begin{array}{l}\text { In vitro study: "sound human maxillary first premolars extracted for periodontal or orthodontic } \\
\text { reasons" page } 470\end{array}$ \\
\hline Fokkinga 2007 & $\begin{array}{l}\text { All teeth were restored with crowns. Comparisons were: i) post versus no post, and ii) different } \\
\text { types of post }\end{array}$ \\
\hline Fokkinga 2008 & $\begin{array}{l}\text { No teeth were restored with crowns. Comparisons were: i) post versus no post, and ii) different } \\
\text { types of post } \\
\text { comes of relevance for this review }\end{array}$ \\
\hline
\end{tabular}

\section{DATA AND ANALYSES}


Comparison 1. Composite + crown versus composite only

\begin{tabular}{llll}
\hline Outcome or subgroup title & No. of studies & $\begin{array}{l}\text { No. of partici- } \\
\text { pants }\end{array}$ & Statistical method \\
\hline $\begin{array}{l}1 \text { All years, failure of the restoration (non- } \\
\text { catastrophic) }\end{array}$ & 1 & $\begin{array}{l}\text { Risk Ratio (M-H, Fixed, } \\
95 \% \mathrm{Cl})\end{array}$ \\
\hline $\begin{array}{l}2 \text { All years, failure of post (non-cata- } \\
\text { strophic) }\end{array}$ & 1 & $\begin{array}{l}\text { Risk Ratio (M-H, Fixed, } \\
95 \% \mathrm{Cl})\end{array}$ \\
\hline
\end{tabular}

Analysis 1.1. Comparison 1 Composite + crown versus composite only, Outcome 1 All years, failure of the restoration (non-catastrophic).

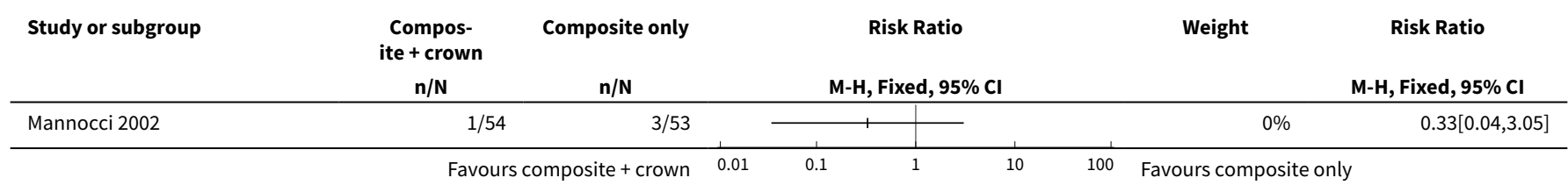

Analysis 1.2. Comparison 1 Composite + crown versus composite only, Outcome 2 All years, failure of post (non-catastrophic).

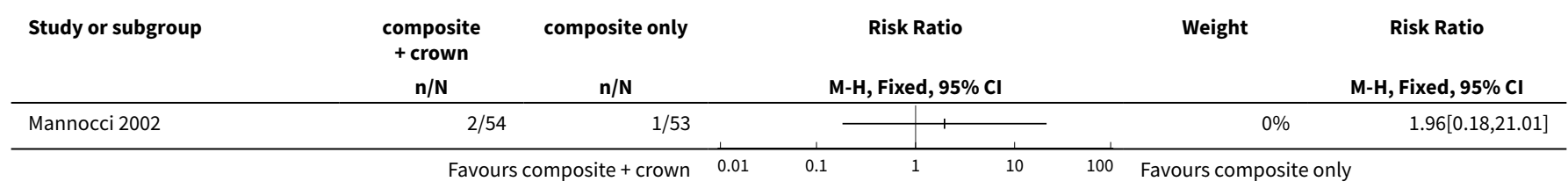

\section{ADDITIONAL TABLES}

Table 1. Proportion of non-catastrophic failures of the restoration (Mannocci 2002)

\begin{tabular}{lll}
\hline Time point & Composite + crown & Composite only \\
\hline From randomisation to the end of year 1 & $0 / 57$ & $0 / 55$ \\
\hline From the start of year 2 to the end of year 2 & $1 / 57$ & $2 / 48$ \\
\hline From the start of year 3 to the end of year 3 & $0 / 54$ & $3 / 53$ \\
\hline From randomisation to the end of year 3 & $1 / 54$ & 2 \\
\hline
\end{tabular}

Table 2. Proportion of non-catastrophic failures of the post (Mannocci 2002)

\begin{tabular}{lll}
\hline Time point & Composite + crown Composite only
\end{tabular}


Table 2. Proportion of non-catastrophic failures of the post (Mannocci 2002) (Continued)

\begin{tabular}{lll} 
From randomisation to the end of year 1 & $0 / 57$ & $0 / 55$ \\
\hline From the start of year 2 to the end of year 2 & $2 / 57$ & $0 / 50$ \\
\hline From the start of year 3 to the end of year 3 & $0 / 54$ & $1 / 53$
\end{tabular}

Table 3. Research recommendations based on a gap in the evidence of single crowns versus conventional fillings for the restoration of root-filled teeth

\begin{tabular}{ll}
\hline Core elements $\quad$ Issues to consider & $\begin{array}{l}\text { Status of research for this review and recommendations for future } \\
\text { research }\end{array}$
\end{tabular}

Evidence (E) What is the current state of ev-

This systematic review identified one RCT, which addressed some of the main outcomes and provided very limited evidence for the comparative effectiveness of single crowns versus conventional fillings for the restoration of root-filled teeth. The single included study was underpowered, of short duration and was judged to be at high risk of bias due to missing outcomes data

\begin{tabular}{|c|c|c|}
\hline $\begin{array}{l}\text { Population } \\
\text { (P) }\end{array}$ & $\begin{array}{l}\text { Diagnosis, disease stage, co- } \\
\text { morbidity, risk factor, sex, age, } \\
\text { ethnic group, specific inclu- } \\
\text { sion or exclusion criteria, clini- } \\
\text { cal setting }\end{array}$ & $\begin{array}{l}\text { Permanent teeth with adequate bony support; without previous en- } \\
\text { dodontic treatment; with preserved cusp structure; in occlusal func- } \\
\text { tion; not used as abutment for fixed or removable partial dentures }\end{array}$ \\
\hline Intervention (I) & $\begin{array}{l}\text { Type, frequency, dose, dura- } \\
\text { tion, prognostic } \\
\text { factor }\end{array}$ & $\begin{array}{l}\text { Metal or metal-ceramic full coverage crowns, adhesive composite core } \\
\text { with or without post (cast or preformed) }\end{array}$ \\
\hline Comparison $(\mathbf{C})$ & $\begin{array}{l}\text { Type, frequency, dose, dura- } \\
\text { tion, prognostic } \\
\text { factor }\end{array}$ & $\begin{array}{l}\text { Any type of filling materials for direct restoration (e.g. amalgam and } \\
\text { composite), or indirect partial restorations (e.g. inlays and onlays) with } \\
\text { or without post }\end{array}$ \\
\hline Outcome (0) & $\begin{array}{l}\text { Which clinical- or patient-re- } \\
\text { lated outcomes will the re- } \\
\text { searcher need to measure, im- } \\
\text { prove, influence or accom- } \\
\text { plish? Which methods of mea- } \\
\text { surement should be used? }\end{array}$ & $\begin{array}{l}\text { USPHS evaluation methods for measuring clinical research perfor- } \\
\text { mance of restorative materials (Bayne 2005). If anterior teeth are in- } \\
\text { volved, outcomes should include participant assessed aesthetic ap- } \\
\text { pearance }\end{array}$ \\
\hline $\begin{array}{l}\text { Time stamp } \\
\text { (T) }\end{array}$ & $\begin{array}{l}\text { Date of literature search or } \\
\text { recommendation }\end{array}$ & 26 March 2015 \\
\hline Study type & $\begin{array}{l}\text { What is the most appropriate } \\
\text { study design to address the } \\
\text { proposed question? }\end{array}$ & $\begin{array}{l}\text { RCT: multicentre, adequately powered } \\
\text { Methods: concealment of allocation sequence } \\
\text { Blinding: outcomes assessors, data analysts (patients, trialists may not } \\
\text { be feasible) } \\
\text { Setting: hospital, university or general practice with adequate fol- } \\
\text { low-up }\end{array}$ \\
\hline
\end{tabular}

$\mathrm{RCT}=$ randomised controlled trial; USPHS = US Public Health Service 


\section{APPENDICES}

\section{Appendix 1. MEDLINE via OVID search strategy}

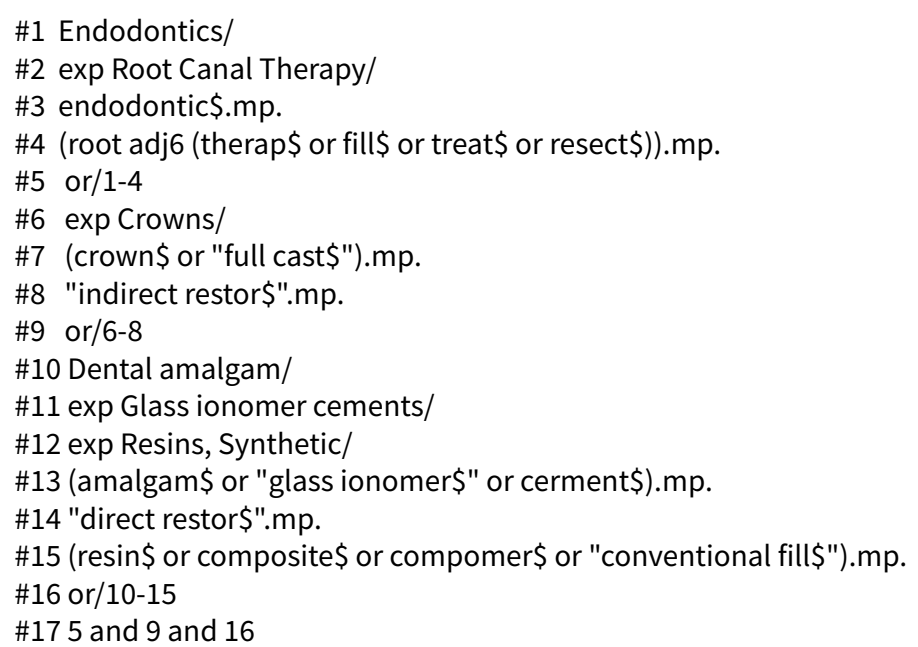

\section{Appendix 2. Cochrane Oral Health Group's Trials Register search strategy}

((endodontic ${ }^{\star}$ or "root canal" or (root and (therap* or fill* or treat* or resect*))) and (crown* or cast or "indirect restor*") and (amalgam* or "glass ionomer" or cerment $^{\star}$ or "direct restor ${ }^{\star}$ or resin ${ }^{\star}$ or composite* or compomer ${ }^{\star}$ or fill $\left.{ }^{\star}\right)$ )

\section{Appendix 3. CENTRAL search strategy}

\#1 MeSH descriptor Endodontics this term only

\#2 MeSH descriptor Root canal therapy explode all trees

\#3 endodontic* in All Text

\#4 ((root in All Text near/6 therap* in All Text) or (root in All Text near/6 fill ${ }^{\star}$ in All Text) or (root in All Text near/6 treat* in All Text) or (root in All Text near/6 resect* in All Text))

\#5 (\#1 or \#2 or \#3 or \#4)

\#6 MeSH descriptor Crowns explode all trees

\#7 (crown* in All Text or "full cast*" in All Text)

\#8 "indirect restor*" in All Text

\#9 (\#6 or \#7 or \#8)

\#10 MeSH descriptor Dental amalgam this term only

\#11 MeSH descriptor Glass ionomer cements explode all trees

\#12 MeSH descriptor Resins, synthetic explode all trees

\#13 (amalgam* in All Text or "glass ionomer*" in All Text or cerment* in All Text)

\#14 "direct restor*" in All Text

\#15 (resin* in All Text or composite* in All Text or compomer* in All Text or fill* in All Text)

$\# 16$ (\#10 or \#11 or \#12 or \#13 or \#14 or \#15)

$\# 17$ (\#5 and \#9 and \#16)

\section{Appendix 4. EMBASE via OVID search strategy}

\section{1. exp Endodontics/}

2. endodontic\$.mp.

3. (root adj6 (therap\$ or fill\$ or treat\$ or resect\$)).mp.

4. or/1-3

5. exp Tooth crown/

6. (crown\$ or "full cast\$").mp.

7. "indirect restor\$".mp.

8. or/5-7

9. Dental alloy/

10. exp Glass ionomer/

11. exp Resin/

12. (amalgam\$ or "glass ionomer\$" or cerment\$).mp.

13. "direct restor\$".mp. 
14. (resin\$ or composite\$ or compomer\$ or fill\$).mp.

15. or/9-14

16.4 and 8 and 15

The above subject search was linked to the Cochrane Oral Health Group filter for EMBASE via OVID:

1. random\$.ti,ab.

2. factorial\$.ti,ab.

3. (crossover $\$$ or cross over $\$$ or cross-over\$).ti,ab.

4. placebo\$.ti,ab.

5. (doubl\$ adj blind\$).ti,ab.

6. (singl\$ adj blind\$).ti,ab.

7. assign\$.ti,ab.

8. allocat\$.ti,ab.

9. volunteer\$.ti,ab.

10. CROSSOVER PROCEDURE.sh.

11. DOUBLE-BLIND PROCEDURE.sh.

12. RANDOMIZED CONTROLLED TRIAL.sh.

13. SINGLE BLIND PROCEDURE.sh.

14. or/1-13

15. ANIMAL/ or NONHUMAN/ or ANIMAL EXPERIMENT/

16. HUMAN/

17. 16 and 15

18. 15 not 17

19. 14 not 18

\section{Appendix 5. CINAHL via EBSCO search strategy}

S1 MH "Endodontics+"

S2 MH "Root canal therapy+"

S3 endodontic*

S4 (root N6 therap ${ }^{\star}$ ) or (root N6 fill*) or (root N6 treat*) or (root N6 resect*)

S5 $\mathrm{S} 1$ or $\mathrm{S} 2$ or S3 or S4

S6 MH "Crownst"

S7 (crown* or "full cast*")

S8 "indirect restor*"

S9 $\mathrm{S} 6$ or $\mathrm{S} 7$ or $\mathrm{S} 8$

S10 MH "Dental amalgam"

S11 MH "Glass ionomer cements+"

S12 MH "Resins, synthetic+"

S13 (amalgam* or "glass ionomer ${ }^{\star}$ or cerment*)

S14 "direct restor*"

S15 (resin* or composite* or compomer* or fill*)

$\mathrm{S} 16 \mathrm{~S} 10$ or $\mathrm{S} 11$ or $\mathrm{S} 12$ or $\mathrm{S} 13$ or $\mathrm{S} 14$ or $\mathrm{S} 15$

S17 S5 and S9 and S16

\section{Appendix 6. LILACS via BIREME Virtual Health Library search strategy}

Mh Endodontics or Mh Endodoncia or Mh Endodontia or Mh Root Canal Therapy or Mh Tratamiento del Conducto Radicular or Mh Tratamento do Canal Radicular or endodon\$ or (root\$ and therap\$) or (root\$ and treat\$) or (root\$ and fill\$) or (root\$ and resect\$) or (radicular and trata\$) [Words] and ((Mh Crowns or Mh Coronas or Mh Coroas or crown\$ or corona\$ or coroa\$ or "full cast\$" or "indirect restor\$") and (Mh Dental Amalgam or Mh Amalgama Dental or Mh Amálgama Dentário or "Dental Amalgam\$" or "Amalgama\$ Dental" or "Amálgama\$ Dentário" or Mh Glass lonomer Cements or "Glass lonomer Cement\$" or Mh Cementos de lonómero Vitreo or "cemento\$ de Ionómero vitreo" or Mh Cimentos de lonômeros de Vidro or "cimento\$ de lonômeros de Vidro" or Mh Resins, Synthetic or resin\$ or Mh Resinas Sintéticas or Mh Resinas Sintéticas or "direct restor\$" or composit\$ or compomer\$ or fill\$)) [Words]

The above search strategy was combined with the Brazilian Cochrane Center filter for identifying randomised controlled trials in LILACs:

((Pt randomized controlled trial OR Pt controlled clinical trial OR Mh randomized controlled trials OR Mh random allocation OR Mh double-blind method OR Mh single-blind method) AND NOT (Ct animal AND NOT (Ct human and Ct animal)) OR (Pt clinical trial OR Ex E05.318.760.535\$ OR (Tw clin\$ AND (Tw trial\$ OR Tw ensa\$ OR Tw estud\$ OR Tw experim\$ OR Tw investiga\$)) OR ((Tw singl\$ OR Tw simple \$ OR Tw doubl\$ OR Tw doble\$ OR Tw duplo\$ OR Tw trebl\$ OR Tw trip\$) AND (Tw blind\$ OR Tw cego\$ OR Tw ciego\$ OR Tw mask\$ OR Tw mascar\$)) OR Mh placebos OR Tw placebo\$ OR (Tw random\$ OR Tw randon\$ OR Tw casual\$ OR Tw acaso\$ OR Tw azar OR Tw aleator\$) OR Mh research design) AND NOT (Ct animal AND NOT (Ct human and Ct animal)) OR (Ct comparative study OR Ex E05.337\$ OR Mh follow- 
up studies OR Mh prospective studies OR Tw control\$ OR Tw prospectiv\$ OR Tw volunt\$ OR Tw volunteer\$) AND NOT (Ct animal AND NOT (Ct human and $\mathrm{Ct}$ animal))) [Words] and

WHAT'S NEW

\begin{tabular}{lll}
\hline Date & Event & Description \\
\hline 6 August 2015 & $\begin{array}{l}\text { New citation required but conclusions } \\
\text { have not changed }\end{array}$ & $\begin{array}{l}\text { No new studies were found for inclusion from the updated } \\
\text { search. Minor edits made. 'Summary of findings' table added. }\end{array}$ \\
\hline 26 March 2015 & New search has been performed & Updated searches run. New author added. \\
\hline
\end{tabular}

\section{CONTRIBUTIONS OF AUTHORS}

Carolina AL Chaves (CC), Patrick Sequeira-Byron (PSB), Raphael F de Souza (RS), Zbys Fedorowicz (ZF) and Eman F Alrowaili (EFA) were responsible for:

- organising the retrieval of papers;

- writing to authors of papers for additional information;

- screening search results;

- screening retrieved papers against inclusion criteria;

- appraising the quality of papers;

- data collection for the review;

- extracting data from papers;

- obtaining and screening data on unpublished studies.

In the original review, Ben Carter (BC), ZF and Mona Nasser (MN) entered the data into RevMan and were responsible for analysis and interpretation of the data; PSB and ZF were responsible for designing, co-ordinating and data management of the review; and all review authors contributed to writing the review. PSB, RS and ZF conceived the idea for the review and are the guarantors for the review.

In the update, Patrick Sequeira-Byron (PSB), Zbys Fedorowicz (ZF) and Eman F Alrowaili (EFA) screened retrieved papers against inclusion criteria and all review authors contributed to writing the review.

\section{DECLARATIONS OF INTEREST}

There are no financial conflicts of interest and the review authors declare that they do not have any associations with any parties who may have vested interests in the results of this review.

\section{SOURCES OF SUPPORT}

\section{Internal sources}

- Department of Preventive, Restorative and Pediatric Dentistry, School of Dental Medicine (ZMK), University of Bern, Switzerland.

\section{External sources}

- Cochrane Oral Health Group Global Alliance, Other.

Through our Global Alliance (http://ohg.cochrane.org), the Cochrane Oral Health Group has received support from: British Association for the Study of Community Dentistry, UK; British Association of Oral Surgeons, UK; British Orthodontic Society, UK; British Society of Paediatric Dentistry, UK; British Society of Periodontology, UK; Canadian Dental Hygienists Association, Canada; Mayo Clinic, USA; National Center for Dental Hygiene Research \& Practice, USA; New York University College of Dentistry, USA; and Royal College of Surgeons of Edinburgh, UK.

- School of Dentistry, The University of Manchester, UK.

- National Institute for Health Research (NIHR), UK.

The NIHR is the largest single funder of the Cochrane Oral Health Group.

Disclaimer: 
The views and opinions expressed therein are those of the authors and do not necessarily reflect those of the NIHR, NHS or the Department of Health.

\section{DIFFERENCES BETWEEN PROTOCOLANDREVIEW}

Objectives changed to the 'effects' of restoration of endodontically treated teeth (with or without post and core) by crowns versus conventional filling materials.

Primary outcomes changed from 'success' to 'failure', and classified as catastrophic failure of the restored tooth or restoration (i.e. leading directly to extraction), and non-catastrophic failure of the restoration (i.e. requiring further treatment).

\section{IN DEX TERMS}

\section{Medical Subject Headings (MeSH)}

${ }^{\star}$ Crowns; *Tooth Root; Dental Restoration, Permanent [ ${ }^{*}$ methods]; Post and Core Technique; Randomized Controlled Trials as Topic; Tooth, Nonvital [*rehabilitation]

\section{MeSH check words}

Adult; Female; Humans; Male; Middle Aged 